\title{
VALIDASI METODE ANALISA PADA PENETAPAN KADAR KOENZIM Q10 DALAM SEDIAAN MIKROEMULSI MENGGUNAKAN METODE SPEKTROPHOTOMETER UV-VIS
}

\author{
Silvi Ayu Wulansari*, Eziah Ika Lubada \\ Akademi Farmasi Surabaya, Surabaya, Indonesia \\ "email: silviayu25@gmail.com
}

Received 12 March 2020

Accepted 18 May 2020

\begin{abstract}
Abstrak
Koenzim Q10 banyak digunakan dalam bidang kosmetika karena dapat digunakan sebagai antioksidan, namun koenzim Q10 memiliki kekurangan yaitu hanya dapat larut dalam minyak dan memiliki ukuran partikel yang besar sehingga sulit untuk masuk pada kulit. Koenzim Q10 diformulasikan dalam sediaan mikroemulsi untuk memperbaiki penetrasi dalam kulit. Untuk menunjang efek terapetik dari sediaan mikroemulsi perlu dikembangkan penetapan kadar koenzim Q10 menggunakan spektrofotometer UV-Vis, menggunakan pelarut [Acetonitril : 2-propanol (84:16)] dan diukur pada panjang gelombag $275 \mathrm{~nm}$. Hasil penelitian menunjukkan bahwa koenzim Q10 linier pada rentang konsentrasi 25,5-153,0 ppm dengan LOD dan LOQ sebesar 5,25 $\mu \mathrm{g} / \mathrm{mL}$ dan $17,48 \mu \mathrm{g} / \mathrm{mL}$. Metode penetapan kadar koenzim Q10 pada sampel mikroemulsi memiliki nilai akurasi dan presisi yang cukup baik dengan rata-rata perolehan kembali 100,70\% dan SD 0,41\%. Spektrofotometer UV-Vis dapat digunakan sebagai metode dalam penetapan kadar koenzim Q10 dalam sediaan mikroemulsi yang memenuhi persyaratan validasi penetapan kadar sediaan farmasi.
\end{abstract}

Katakunci: Validasi, koenzim Q10, mikroemulsi, penetapan kadar, spektrofotometri UVVis

\begin{abstract}
Coenzyme Q10 is widely used in cosmetics because it can be used as an antioxidant, but coenzyme Q10 has the disadvantage of being soluble in oil and having a large particle size making it difficult to enter the skin. Coenzyme Q10 is formulated in microemulsion preparations to improve penetration in the skin. To support the therapeutic effect of microemulsion preparations, it is necessary to develop levels of Coenzyme Q10 using a UvVis spectrophotometer, using a [Acetonitril: 2-propanol (84:16)] solvent and measured at a $275 \mathrm{~nm}$ wave length. The results showed that linear coenzyme Q10 in the concentration range of $25.5-153.0 \mathrm{ppm}$ with LOD and LOQ was $5.25 \mu \mathrm{g} / \mathrm{mL}$ and $17.48 \mu \mathrm{g} / \mathrm{mL}$. The method of determining the levels of coenzyme Q10 in microemulsion samples has good accuracy and precision with an average recovery rate of $100.70 \%$ and SD $0.41 \%$. UV-Vis spectrophotometer can be used as a method in determining the levels of coenzyme Q10 in microemulsion preparations that meet the validation requirements for the determination of pharmaceutical dosage levels.
\end{abstract}

Keywords: Validation, coenzyme Q10, microemulsion, determination of dosage level, spectrophotometer $U V$-Vis 


\section{Pendahuluan}

Kemajuan ilmu pengetahuan dan teknologi menyebabkan bentuk sediaan telah berevolusi dari campuran sederhana dan pil, menjadi sistem yang sangat canggih, yang dikenal sebagai sistem pengiriman obat baru. Mikroemulsi adalah sistem pengiriman obat baru yang terdiri dari sistem emulsi minyak dan air dengan rata-rata diameter droplet mulai dari 50$1000 \mathrm{~nm}$. Biasanya, ukuran droplet ratarata adalah antara $100-500 \mathrm{~nm}$ dan dapat berupa bentuk minyak dalam air $(\mathrm{m} / \mathrm{a})$ atau air dalam minyak $(\mathrm{a} / \mathrm{m})$ (Chime et al., 2014).

Koenzim Q10 atau ubiquinon merupakan vitamin dan antioksidan larut lemak yang berguna untuk meningkatkan produksi energi di dalam sel mitokondria. Pada kulit konsentrasi koenzim Q10 10 kali lebih tinggi pada epidermis dari pada di dermis (Montenegro, 2014). Sebagai bahan kosmetik koenzim Q10 bertindak sebagai antioksidan yang dapat melindungi tubuh dari kerusakan diakibatkan. oleh molekul berbahaya yang biasanya disebut radikal bebas (Kapoor A. \&Kapoor P., 2013). Koenzim Q10 memiliki kekurangan yaitu hanya dapat larut dalam minyak dan memiliki ukuran partikel yang besar sehingga sulit untuk masuk pada kulit. Koenzim Q10 diformulasikan dalam sediaan mikroemulsi untuk memperbaiki penetrasi dalam kulit (Deapsari, 2016). Untuk menunjang efek terapetik dari sediaan mikroemulsi perlu dilakukan penetapan kadar Koenzim Q10 untuk menjamin kualitas sediaan mikroemulsi, oleh karena itu diperlukan sebuah metode penetapan kadar koenzim Q10 menggunakan pelarut yang sesuai untuk bisa memisahkan koenzim Q10 dari kandungan-kandungan yang ada di dalam mikroemulsi. Metode ini belum pernah dilakunakan untuk penetapan kadar koenzim Q10 dalam mikroemulsi maka diperlukan validasi metode terlebih dahulu sebelum dilakukan penetapan kadar untuk sediaan mikroemulsi yang mengandung koenzim
Q10.

Validasi metode bertujuan utuk mengetahui apakah metode yang digunakan untuk penetapan kadar koenzim Q10 dalam sediaan mikroemulsi ini sahih atau valid dilihat dari parameterparameter tertentu. Parameter yang digunakan untuk menentukan validasi dari metode penetapan kadar ini adalah akurasi, presisi, spesifitas, linieritas, LOQ dan LOQ. Parameter tersebut merupakan syarat parameter analisis yang harus dipenuhi untuk prosedur analisis kategori I. Kategori I mencakup prosedur analisis kuantitatif untuk menetapkan kadar komponen utama bahan obat atau zat aktif dalam sediaan farmasi (Anonim, 2007).

\section{Metode Penelitian \\ Alat dan bahan}

Peralatan yang digunakan dalam penelitian ini meliputi Timbangan analitik (ACIS AD-300i), Botol timbang, Beaker glass (Pyrex), Labu ukur (Pyrex), Tabung reaksi, Vortex, Mikro Pipet 1000 $\mu 1$, Milipore $0,45 \mu \mathrm{m}$, Spektrofotometri UVVis (Genesys 10S).

Bahan yang digunakan dalam penelitian ini adalah koenzim Q10 (Chemco), mikroemulsi koenzim Q10, water for injection, asetonitril (Merck), 2-propanol (Merck).

Pembuatan stok larutan standar koenzim Q10 $(500 \mu \mathrm{g} / \mathrm{ml})$

Pembuatan stok larutan standar Koenzim Q10 dilakukan dengan cara timbang $5 \mathrm{mg}$, dimasukkan ke dalam labu ukur $10 \mathrm{ml}$, kemudian ditambahkan pelarut [Acetonitril : 2-propanol (84:16)] (Mahendra, et al., 2011) sampai batas 10 $\mathrm{mL}$ pada labu ukur dan dikocok sampai homogen dan diberi label penandaan (500 $\mu \mathrm{g} / \mathrm{mL}$ koenzim Q10).

\section{Penetapan panjang gelombang maksimal}

Larutan standar dipipet 1,5 ml larutan tersebut kemudian dibaca absorbansinya dengan menggunakan spektrofotometer UV-Vis pada panjang gelombang $(\lambda) 200$ 
$400 \mathrm{~nm}$. Absorbansi tertinggi yang diperoleh dapat digunakan sebagai $(\lambda)$ maksimum.

\section{Pembuatan larutan kurva baku}

Disiapkan larutan kurva baku yang mengandung $25 ; 50 ; 75 ; 100 ; 125 ; 150$ $\mu \mathrm{g} / \mathrm{ml}$ koenzim Q10, dengan cara dipipet masing-masing: 0,$5 ; 1 ; 1,5 ; 2 ; 2,5 ; 3 \mathrm{ml}$ larutan stok standart koenzim Q10 dengan menggunakan pipet volume dan dimasukkan masing-masing kedalam labu ukur $10 \mathrm{ml}$. Masing-masing ditambahkan dengan pelarut [Acetonitril : 2-propanol (84:16)] sampai batas $10 \mathrm{ml}$, dikocok sampai homogen dan diberi label pada setiap labu ukur.

Metode validasi linieritas, LOD, LOQ, akurasi, presisi dan perolehan kembali

Pengujian LOD dan LOQ untuk menentukan batas terendah konsentrasi standar, baik yang dapat dianalisis secara kualitatif (LOD) maupun secara kuantitatif (LOQ). Perhitungan LOD dan LOQ dari standar deviasi (SD) dan slope dari persamaan regresi kurva baku (S), dengan perhitungan sebagai berikut: $\mathrm{LOD}=3,3$ $(\mathrm{SD} / \mathrm{S})$ dan $\mathrm{LOQ}=10(\mathrm{SD} / \mathrm{S})$.

Penentuan rentang dan linieritas diperoleh dari kurva baku yang dibuat, dengan memplot data perbandingan absorbansi (y) dengan konsentrasi larutan (x). Dari data yang diperolehdilakukan perhitungan untuk mendapatkan persamaan regresi dan koefisien korelasi (r). Koefisien korelasi (r) $\geq 0,99$ (Rochman, 2016).

Pengujian akurasi dan presisi dilakukan dengan meggunakan metode spike membuat sediaan dengan rentang konsentrasi 0,$8 ; 1 ; 1,2$ gram koenzim Q10 ( $80 \% ; 100 \%$; 120\% ) dan konsentrasi akhir sediaan adalah $80 ; 100 ; 120 \mu \mathrm{g} / \mathrm{ml}$ koenzim Q10. Masing-masing konsentrasi dibuat 3 replikasi kemudian di dibaca absorbansinya dengan menggunakan spektrofotometer UV-Vis pada panjang gelombang $(\lambda)$ maksimum. Hasil absorbansinya digunakan untuk menghitung harga perolehan kembali (recovery) dengan standar deviasi (SD) dan standar deviasi relative (RSD) $\leq 2,7 \%$. Bandingkan nilai persen perolehan kembali dengan keterimaan persen perolehan standar (AOAC, 2016). Analisa dilakukan pada hari yang sama (interday) dan selanjutnya akan dianalisa pada 3 hari yang berbeda secara berturut-turut (intraday).

\section{Penetapan kadar koenzim Q10 dalam mikroemulsi}

Dipipet 0,2 $\mathrm{ml}$ sampel dari 4 formula mikroemulsi masing-masing dimasukkan ke dalam tabung reaksi $10 \mathrm{ml}$, ditambahkan pelarut [Acetonitril : 2propanol (84:16)] sampai batas $10 \mathrm{ml}$ dan di kocok sampai homogen, kemudian sampel divortex selama 2 menit dan disonifikasi selama 2 menit kemudian difiltrasi menggunakan membran filter $0,45 \mu \mathrm{m}$ diperoleh supernatan dan diberi label sampel terlebih dahulu. Masingmasing sampel diamati dengan menggunakan spektrofotometer UV-Vis pada panjang gelombang $(\lambda)$ makasimum. Hasil absorbansinya digunakan untuk menghitung harga perolehan kembali (recovery) dengan standar deviasi (SD) dan standar deviasi relatif (RSD) $\leq 2,7 \%$.

\section{Hasil dan Pembahasan}

\section{Larutan baku koenzim Q10}

Larutan baku koenzim Q10 dengan konsentrasi tertentu dibuat dengan cara melarutkan bahan koenzim Q10 dengan pelarut [Acetonitril : 2-propanol (84:16)] (Mahendra, et al., 2011). Penggunaan kombinasi pelarut dalam melarutkan koenzim Q10 dikarenakan koenzim Q10 sangat sukar larut dalam pelarut polar.

Penentuan panjang gelombang maksimum ( $\lambda$ maks) pada koenzim $Q 10$

Panjang gelombang maksimum $(\lambda$ maks) merupakan panjang gelombang dimana terjadi eksitasi elektronik yang memberikan absorbansi maksimum. Alasan dilakukan pengukuran pada 
panjang gelombang maksimum adalah perubahan absorban untuk setiap satuan kosentrasi adalah paling besar pada panjang gelombang maksimum, sehingga akan diperoleh kepekaan analisis yang maksimum. Penentuan panjang gelombang pada penelitian ini dilakukan dengan mengukur absorbansi dari koenzim Q10 pada panjang gelombang ultraviolet yaitu antara panjang gelombang $200 \mathrm{~nm}-$ 400nm. Hasil spektrum senyawa koenzim Q10 dapat dilihat pada Gambar 1.

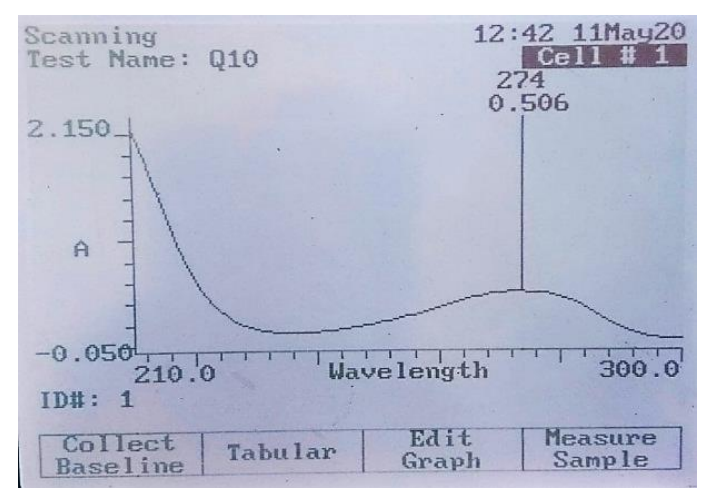

Gambar 1. Spektrum senyawa koenzim Q10

Berdasarkan hasil pengukuran diperoleh panjang gelombang maksimum adalah $274 \mathrm{~nm}$. Secara teoritis serapan maksimum koenzim Q10 adalah $275 \mathrm{~nm}$ (Eman S. et al., 2016). Terjadi pergeseran ( $\lambda$ maks) karena pada koenzim Q10 memiliki gugus auksokrom yang terikat pada gugus kromofor yang bisa menyebabkan pergeseran pada panjang gelombang maksimum.

\section{Uji validasi metode analisa}

\section{Linieritas}

Kurva kalibrasi dibuat enam konsentrasi yang mengandung koenzim Q10 25,0; 50,0; 75,0; 100,0; 125,0; 150,0 $\mu \mathrm{g} / \mathrm{ml}$. Masing-masing konsentasi diamati sebanyak tiga kali replikasi. Kurva kalibrasi dibuat dengan memplot data absorbansi (y) dengan konsentrasi larutan (x). Dari data yang diperoleh dilakukan perhitungan untuk mendapatkan persamaan regresi dan koefisien korelasi (r). Persamaan regresi kurva kalibrasi koenzim Q10 adalah y =0,0151x $+0,2039$ dengan koefisien korelasi 0,9992. Koefisien korelasi (r) dalam penelitian ini sudah memenuhi persyaratan, standar koefisien korelasi (r) $\geq 0,99$ (Rohman, 2016). Hasil linearitas kurva kalibrasi koenzim Q10 dilihat pada Gambar 2, sedangkan data absorbansi pada kurva kalibrasi koenzim Q10 dapat dilihat pada Tabel 1.

Tabel 1. Hasil uji linieritas kurva kalibrasi koenzim Q10

\begin{tabular}{ccc}
\hline $\begin{array}{c}\text { Sampel } \\
(\mathbf{p p m})\end{array}$ & Replikasi & Absorbansi \\
\hline & 1 & 0.589 \\
25,5 & 2 & 0.586 \\
& 3 & 0.581 \\
& 1 & 0.952 \\
51,0 & 2 & 0.951 \\
& 3 & 0.954 \\
& 1 & 1.373 \\
76,5 & 2 & 1.374 \\
& 3 & 1.375 \\
& 1 & 1.772 \\
102,0 & 2 & 1.776 \\
& 3 & 1.777 \\
127,5 & 1 & 2.128 \\
& 2 & 2.129 \\
& 3 & 2.134 \\
153,0 & 1 & 2.493 \\
& 2 & 2.491 \\
& 3 & 2.499 \\
\hline
\end{tabular}

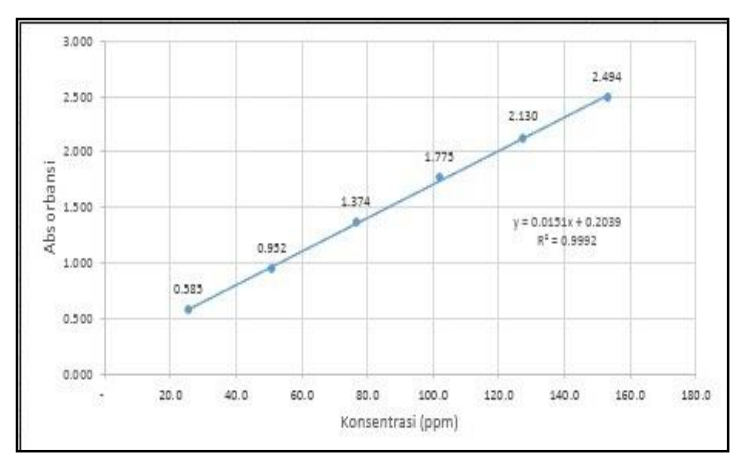

Gambar 2. Kurva linieritas kalibrasi koenzim Q10 
Batas deteksi (LOD) dan batas kuantitasi (LOQ)

Batas deteksi (LOD) dan batas kuantitasi (LOQ) ditentukan pada rentang linieritas. Perhitungan LOD dan LOQ dari standar deviasi (SD) dan slope dari persamaan regresi kurva baku (S), dengan perhitungan sebagai berikut: $\mathrm{LOD}=3,3$ $(\mathrm{SD} / \mathrm{S})$ dan $\mathrm{LOQ}=10(\mathrm{SD} / \mathrm{S})$. Hasil LOD koenzim Q105,25 $\mu \mathrm{g} / \mathrm{ml}$ dan LOQ 17,48 $\mu \mathrm{g} / \mathrm{ml}$, data LOD dan LOQ dapat dilihat pada Tabel 2.

Tabel 2. Hasil pengujian LOD dan LOQ

\begin{tabular}{cc}
\hline Item & Absorbansi \\
\hline $\mathrm{r}$ & 0,9992 \\
$\mathrm{SD}$ & 0,0264 \\
$\operatorname{LOD}(\mu \mathrm{g} / \mathrm{ml})$ & 5,25 \\
$\operatorname{LOQ}(\mu \mathrm{g} / \mathrm{ml})$ & 17,48 \\
\hline
\end{tabular}

Akurasi dan presisi

Data hasil uji presisi dan akurasi untuk sampel mikroemulsi dapat dilihat pada Tabel 3. Hasil penentuan akurasi, diperoleh rata-rata persen perolehan koenzim Q10 adalah 100,70\% dan rentang persen perolehan kembali yang didapat adalah 99,98-101,29\%, di mana persyaratan persen perolehan kembali yang dapat diterima adalah 97-103\% (AOAC, 2016). Hal itu menunjukkan perolehan kembali untuk parameter akurasi dan presisi telah memenuhi persyaratan yang telah ditentukan. Pada penentuan akurasi dan presisi, didapatkan nilai RSD 0,041\%. Nilai RSD tersebut memenuhi kriteria penerimaan yang ditentukan yaitu tidak lebih dari $2 \%$ (Snyder et al., 2010). Dengan demikian keterulangan dan peroleh kembali untuk koenzim Q10 pada parameter akurasi dan presisi telah memenuhi persyaratan validasi.

Tabel 3. Hasil uji akurasi dan presisi

\begin{tabular}{ccccc}
\hline \multirow{2}{*}{ Preparasi Sampel } & \multirow{2}{*}{ Replikasi } & \multicolumn{3}{c}{ \% Recovery (Hari ke- ) } \\
\cline { 3 - 5 } & & $\mathbf{1}$ & $\mathbf{2}$ & $\mathbf{3}$ \\
\hline \multirow{2}{*}{$80 \mathrm{ppm}$} & 1 & 100.86 & 100.26 & 100.43 \\
& 2 & 101.29 & 101.09 & 101.34 \\
\multirow{3}{*}{$100 \mathrm{ppm}$} & 3 & 100.28 & 101.58 & 101.04 \\
& 1 & 100.74 & 100.33 & 100.06 \\
& 2 & 101.05 & 100.29 & 100.76 \\
$120 \mathrm{ppm}$ & 3 & 99.98 & 101.09 & 100.59 \\
& 1 & 100.78 & 100.17 & 100.39 \\
& 2 & 100.87 & 100.84 & 100.93 \\
& 3 & 100.48 & 100.53 & 100.89 \\
\hline
\end{tabular}

Penetapan kadar koenzim Q10 pada mikroemulsi

Pada penelitian ini konsentrasi koenzim Q10 yang dianalisis dalam mikroemulsi sebesar 1\% b/v). Hasil kadar Koenzim Q10 dapat dilihat di Tabel 4. Hasil kadar koenzim Q10 pada sampel mikroemulsi yaitu $100,11 \% \quad(\mathrm{~F} 1) ; \quad 100,52 \% \quad(\mathrm{~F} 2)$; $100,19 \%(\mathrm{~F} 3)$ dan $100,48 \%(\mathrm{~F} 4)$ dan ratarata perolehan kembali koenzim Q10 adalah $100,32 \%$, itu menunjukkan perolehan kembali untuk koenzim Q10 telah memenuhi persyaratan yang telah ditentukan di mana rentang perolehan kembali senyawa dengan konsentrasi $1 \%$ b/b yang dapat diterima adalah $97-103 \%$ (AOAC, 2016). Nilai RSD pada penetapan kadar koenzim Q10 adalah $0,0042 \%$, dan telah memenuhi kriteria penerimaan yang ditentukan yaitu tidak lebih dari 2\% (Snyder et al., 2010). Dengan demikian keterulangan dan peroleh kembali untuk koenzim Q10 telah memenuhi persyaratan validasi. 
Tabel 4. Hasil uji penetapan kadar koenzim Q10 pada sediaan mikroemulsi

\begin{tabular}{ccccc}
\hline Sampel & Replikasi & Absorbansi & \% Kadar & $\begin{array}{c}\text { Rata-Rata } \\
\text { \%Perolehan kembali }\end{array}$ \\
\hline \multirow{2}{*}{ F1 } & 1 & 1.712 & 99.92 & 100.11 \\
& 2 & 1.716 & 100.14 & \\
F2 & 3 & 1.718 & 100.27 & 100.52 \\
& 1 & 1.732 & 101.21 & \\
F3 & 3 & 1.713 & 99.95 & 100.19 \\
& 1 & 1.719 & 100.39 & \\
F4 & 3 & 1.720 & 100.41 & 100.48 \\
& 1 & 1.716 & 100.18 & \\
\hline
\end{tabular}

\section{Kesimpulan}

Berdasarkan penelitian yang telah dilakukan dapat disimpulkan bahwa penetapan kadar koenzim Q10 dalam sediaan mikroemulsi dapat dilakukan dengan menggunakan metode spektrofotometer UV-Vis. Metode penetapan kadar yang digunakan telah memenuhi persyaratan validasi metode analisa. Hasil rata-rata persen perolehan koenzim Q10 pada parameter Akurasi dan Presisi adalah 100,70\% masuk dalam rentang perolehan kembali yang didapat diterima (99,98-101,29\%). Hasil rata-rata perolehan kembali pada penetapan kadar koenzim Q10 dalam sediaan mikroemulsi adalah $100,32 \%$ yang masuk dalam rentang perolehan kembali yang didapat diterima yaitu (97-103\%).

\section{Daftar Pustaka}

Anonim. 2007. Farmakope Herbal edisi I, Departemen Kesehatan RI, Jakarta.

Association of Official Analytical Chemists (AOAC). 2016. Official Methods of Analysis. (20th Ed.). Washington Dc: Association of Official Analytical Chemist Inc.

Chime, S., Kenechukwu, F., \& Attama, A. 2014. Nanoemulsions-Advances in Formulation, Characterization and

\section{Saran}

Disarankan untuk peneliti selanjutnya melakukan optimasi macam pelarut yang digunakan untuk ekstrasi koenzim Q10 pada sediaan mikroemulsi uji validasi metode analisa penetapan kadar koenzim Q10 menggunakan alat yang tidak terpengaruh oleh adanya gugus kromofor seperti HPLC atau alat lain yang lebih spesifik.

\section{Ucapan Terima Kasih}

Penulis mengucapkan terimakasih kepada Akademi Farmasi Surabaya selaku institusi yang memfasilitasi dan memberikan banyak dukungan untuk penulis dapat menyelesaikan penelitian ini.

applications in drug delivery. In: Ali, D.S., Application of Nanotechnology in Drug Delivery. Croatia: In Tech, 77-111.

Deapsari, F. 2016. Efektivitas Nanoemulsi sebagai Penghantar Coenzym Q10 sebagai Kosmetika Antiaging (Dengan menggunakan fase minyak Olive Oil). Tesis. Universitas Airlangga. 
Eman S. E., \& Rania S. A. 2016. Validation and application of Vierordt'sspectrophotometric method for simultaneous estimation of tamoxifen/coenzyme Q10 in theirbinary mixture and pharmaceutical dosage forms. Asian Journal of Pharmaceutical Sciences, 11(2), 318-325

Kapoor, P., \& A. K., Kapoor. 2013, Coenzyme Q10 - A Novel Molecule, Journal, Indian Academy of Clinical Medicine, 14 (1), 37-45

Mahendra, K., Murthy, Y.L.N., et.al. 2011, Determination of Coenzym Q10 and its synthesis releated impurities by High Performance liquid Chromatography (HPLC) and Mass Spectrometry (MS), International Journal of Pharm Tech Research, 3 (3), 1468-1477.

Martonegoro, L. 2014. Nanocarriers for skin Delivery of cosmetic Antioxidant. Journal of Pharmacy \& Pharmacognosi Research, 73-92.

Rochman, A. 2016. Validasi dan Penjaminan Mutu Metode Analisis.Kimia. Yogyakarta: UGM Press.

Snyder, L. R., Kirkland, J. J., Dolan J.W., 2010. Introduction to Modern Liquid Chromatography, 3th Ed. USA:John Wiley \& Sons, Inc. Publication. 